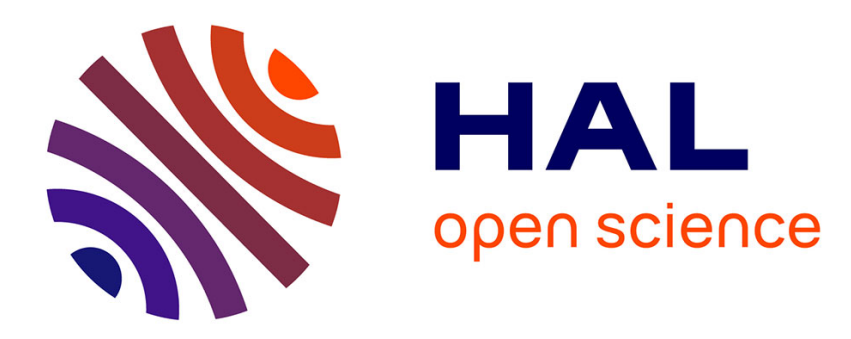

\title{
L'action cinématographique française en Roumanie de 1945 à la Guerre froide
}

\author{
Aurelia Vasile
}

\section{To cite this version:}

Aurelia Vasile. L'action cinématographique française en Roumanie de 1945 à la Guerre froide. Relations internationales, inPress, 2 (166), pp.117 - 136. 10.3917/ri.166.0117 . halshs-01375612

\section{HAL Id: halshs-01375612 \\ https://shs.hal.science/halshs-01375612}

Submitted on 5 Jan 2020

HAL is a multi-disciplinary open access archive for the deposit and dissemination of scientific research documents, whether they are published or not. The documents may come from teaching and research institutions in France or abroad, or from public or private research centers.
L'archive ouverte pluridisciplinaire HAL, est destinée au dépôt et à la diffusion de documents scientifiques de niveau recherche, publiés ou non, émanant des établissements d'enseignement et de recherche français ou étrangers, des laboratoires publics ou privés. 


\section{L'action cinématographique française en Roumanie de 1945 à la Guerre froide}

De la seconde moitié du XIX ${ }^{\mathrm{e}}$ siècle à la Seconde Guerre mondiale, la France a exercé une influence constante dans les Balkans, en particulier en Roumanie où sa présence a été encouragée et soutenue par les élites culturelles et politiques locales ${ }^{1}$. Si, dans ses dimensions économiques, cette influence peut s'inscrire dans l'« impérialisme à la française ", l'action et l'influence culturelle, elles, ont été analysées plutôt en termes de "messianisme» ou d'acculturation ${ }^{2}$. La meilleure illustration du regard porté par les élites roumaines sur cette influence, concurrencée toutefois par le modèle germanique, est donnée par l'historien roumain, Lucian Boia :

Il s'agit de beaucoup plus que d'un modèle culturel et d'un processus d'acculturation. Ce fut une vraie passion, une histoire d'amour (du moins de la part des Roumains). La France devient un mythe qui joua un rôle moteur dans la modernisation de la société roumaine. L'élite du pays aspirait à rapprocher la Roumanie le plus possible de cette formule "indépassable» de civilisation qui semblait être figurée par la France (l'alternative étant le modèle allemand qui eut aussi ses partisans, mais ceux-ci ne réussirent pas à ébranler la francophilie fondamentale de la majorité des Roumains) $»^{3}$.

À la sortie de la Seconde Guerre mondiale cependant, la position politique de la France sur le plan international est sérieusement fragilisée. S' « il n'y a aucune marge de manœuvre pour une politique de grandeur », les affaires culturelles semblent être, malgré tout, le domaine à même d'offrir à la France un authentique moyen d'influence ${ }^{4}$. Elle s'appuie pour ce faire sur des institutions culturelles amplement restructurées et une politique culturelle active, en général et en Roumanie en particulier, un pays représentant une position d'autant plus précieuse que la position culturelle de la France a pu y être en bonne partie préservée durant les années 1940$1944^{5}$.

${ }^{1}$. Le rôle de la France comme modèle politique et culturel dans le processus roumain de modernisation a été amplement traité dans l'historiographie roumaine. Quelques titres des plus représentatifs: Alexandru Zub, Dumitru Ivanescu (dir.), Franţa, model cultural şi politic (La France, modèle culturel et politique), Iasi, Junimea, 2003 ; Dan Berindei, «Les Roumains et la France au carrefour de leur modernité », Études Danubiennes, $\mathrm{n}^{\circ}$ 1-2, 2002 ; Traian Sandu, La Grande Roumanie, alliée de la France? Une péripétie diplomatique des Années Folles (1919 - 1933), Paris, L’Harmattan, 1999 ; Ramona Bordei-Boca (dir.), Francophonie roumaine et intégration européenne, Dijon, AUF, 2006.

2. Jean Bouvier, René Girault, Jacques Thobie, L'impérialisme à la française, Paris, La Découverte, 1986 ; pour la notion de «messianisme »: Albert Salon, L'Action culturelle de la France dans le monde. Analyse critique, thèse pour le doctorat d'État, Université Paris 1, 1981, pp. 102, 114 ; pour celle d' « acculturation » : Anne Dulphy, Robert Frank, Marie-Anne Matard-Bonucci, Pascal Ory (dir.), Les Relations culturelles internationales au XX siècle : de la diplomatie culturelle à l'acculturation, Bruxelles, Berne, Berlin, PIE Peter Lang, 2010.

3. Lucian Boia, «Le petit Paris : Bucarest réel-Bucarest imaginaire », in Ramona Bordei-Boca (dir.), op. cit., p. 207.

${ }^{4}$. Citation de Robert Frank, « La France et son rapport au monde au XX ${ }^{\mathrm{e}}$ siècle », Politique étrangère, $\mathrm{n}^{\circ}$ 3-4, 2000, p. 832 .

5. Avec la Tchécoslovaquie et la Pologne, la Roumanie fait partie des priorités de la France dans ses actions culturelles à l'est de l'Europe. Annie Guénard, La Présence culturelle française en Europe centrale et orientale 
Si le Quai d'Orsay a pu créer des points d'ancrage très forts dans la culture roumaine dans les domaines du livre ou de l'enseignement avant la guerre, le cinéma n'a pas bénéficié de la même attention ${ }^{6}$. Le potentiel marchand du film lui conférait une autonomie importante dans sa circulation internationale, l'exportation étant assurée par les maisons de production françaises ou étrangères et les distributeurs privés. Les faiblesses du réseau de distribution, l'empressement des producteurs français à céder leurs films aux maisons de distribution étrangères et le peu d'implication de la part des autorités publiques amenaient le film français, pourtant très prisé par les spectateurs roumains, à la troisième place sur le marché de l'exploitation, après les films américains et allemands ${ }^{7}$. Le ministère des Affaires étrangères s'intéressa très tardivement au cinéma, et en privilégiant "les actualités », susceptibles de contribuer d'une manière plus contrôlée à la diffusion de l'image de la France, son principal objectif $^{8}$. La distribution des films procédait donc d'une action désordonnée, parfois chaotique, inscrite dans une logique de marché libre ; elle était assurée d'une part par de grandes sociétés internationales (Pathé, Gaumont, Paramount, Universal, MGM et, pendant la guerre, Continental) et d'autre part, par des distributeurs locaux, des propriétaires de salles de cinéma ou des investisseurs privés dans le secteur cinématographique.

Cette étude se propose d'analyser les ressorts de la présence cinématographique française en Roumanie dans une perspective d'histoire de relations internationales et d'histoire culturelle. Nous examinerons les stratégies françaises destinées à renforcer et préserver sa présence cinématographique après 1945, les atouts et les faiblesses de cette dernière dans un contexte de pressions et de concurrence tant anglo-américaine que soviétique. Nous étudierons également les réactions de la Roumanie en tant que pays récepteur et/ou consommateur au travers des initiatives des structures étatiques centrales et locales. Et tout cela dans le contexte politique mouvant des années 1945-1948.

Ces années, où toutes les évolutions paraissaient possibles, suscitant des alternances d'espoirs et d'inquiétudes, sont traversées en effet par de fortes tensions internationales issues des stratégies géopolitiques développées par les alliés victorieux pour gérer le retour à la paix. C'est également la période où tous les pays, tant sur le plan interne qu'international, connaissent d'importantes luttes de pouvoir et adoptent successivement des tactiques de prudence, de modération ou d'affrontement. Bien qu'exclue du concert des grandes puissances, la France entend jouer un rôle majeur sur la scène internationale avec ses propres outils et atouts. Elle adopte surtout un positionnement différent de celui de ses alliés, jouant jusqu'en 1947 la carte de la neutralité, cherchant à établir des alliances à la fois avec l'URSS et les Anglo-Américains. La politique de la France en Roumanie à partir de 1945 illustre sa volonté de réaffirmer son influence, surtout culturelle et de renouer avec les pratiques d'avant-guerre.

La Roumanie, en revanche, se place depuis l'automne 1944 sous l'influence soviétique et voit la montée au pouvoir du Parti communiste roumain (PCR), complètement appuyé par Moscou. Néanmoins, jusqu'à la fin de l'année 1947, le PCR, dont les effectifs gonflent entre

avant et après la Seconde Guerre mondiale (1936-1940, 1944-1949), thèse de doctorat, Université Paris 1, 1992 , pp. 499, 417-475. Également, Ana-Maria Stan, La France de Vichy et la Roumanie (1940-1944) : collaboration et conflits, Cluj-Napoca, Centre d'études transylvaines, 2007 (en roumain), à l'origine thèse de doctorat en cotutelle entre l'Université Babes-Bolyai, Cluj-Napocas et l'Université Paris IV-Sorbonne, 2005); Adriana Bichiş, Les Relations diplomatiques franco-roumaines pendant la Deuxième Guerre mondiale, thèse de doctorat, Université Babes-Bolyai, Cluj-Napoca, 2013.

${ }^{6}$. Albert Salon, op. cit., pp. 47-173 ; Annie Guénard, op. cit., pp. 55-88, 140-159.

7. François Garçon, La Distribution cinématographique en France. 1907-1957, Paris, CNRS Éditions, 2006, p. 133 ; Robert Cravenne, Le Tour du monde du cinéma français. Histoire du cinéma français à l'étranger, Paris, Dixit, 1995, p. 18.

${ }^{8}$. Les grands acteurs français de la distribution souffrent d'un manque de contrôle des marchés (internes et externes) dû à l'absence de réseaux et de circuits de salles. Jacques Choukroun, « Pour une histoire économique du cinéma français », Vingtième Siècle. Revue d'histoire, n 46, 1995. p. 181. Également Annie Guénard, op. cit. pp. 217, 206-210, 223. 
1944 et 1947, partage le pouvoir avec d'autres forces politiques de gauche. Le pluripartisme et la présence de la Commission allié de contrôle de janvier 1946 à septembre 1947 créent les conditions d'une reprise des relations diplomatiques et économiques plus au moins sur le mode libéral d'avant-guerre. L'ambiguïté caractérise cette période et nous essayerons de rendre compte des marges de manœuvre dont disposent alors les acteurs de la distribution cinématographique et de la diplomatie française ainsi que les perspectives qui leur sont ouvertes. Ce faisant, nous apporterons quelques nuances aux approches d'une certaine historiographie roumaine largement tributaire d'une vision téléologique de l'histoire. Pour elle, la présence anglo-américaine n'aurait eu qu'un rôle décoratif en Roumanie et l'influence soviétique se serait manifestée sans entraves depuis août 1944. Sans contester le rôle primordial du haut-commandement soviétique, dont l'importance croît à mesure que se dégradent les relations américano-soviétiques, notre démarche tente de rendre compte du contexte de grande incertitude dans lequel agissent les acteurs diplomatiques politiques et culturels en cette période.

À partir de l'automne 1947, la présence et la pression idéologique soviétiques influent davantage sur les décisions roumaines. Dans ce nouveau contexte, la France se voit obligée d'adapter ses objectifs en Roumanie, veillant à ménager les susceptibilités des Soviétiques tout en continuant de diffuser ses œuvres culturelles. Cette action trouve son terme en 1948, lorsque la Roumanie rompt de manière officielle ses relations avec la France et que le concept de Guerre froide prend tout son sens, ce qui justifie que nous arrêtions là notre étude.

Dernière précision: nous privilégierons le terme d' "actions cinématographiques », comme le fait André Salon dans sa thèse, pour qualifier tant l'activité des sociétés privées et de la diplomatie française que les diverses réactions des sociétés et administrations roumaines ${ }^{9}$. En revanche, nous réserverons le terme de «politiques cinématographiques » aux mesures plus ou moins poussées, plus ou moins radicales, entreprises par l'État roumain dans le domaine du cinéma, surtout à partir de 1948. Bien qu'il s'agisse indéniablement d'une mise au pas du cinéma et de sa subordination aux prescriptions idéologiques du nouveau pouvoir communiste, les multiples initiatives législatives, les campagnes de popularisation et de diffusion du film, la mobilisation de nombreux acteurs publics, les démarches et les structures visant à démocratiser l'accès au film justifient l'emploi de l'expression «politiques cinématographiques ».

\section{LA REPRISE DES RELATIONS COMMERCIALES DANS L'APRÉS-GUERRE, ENTRE INITIATIVES PRIVÉES ET INTERVENTIONS ÉTATIQUES}

\section{Un après-guerre renouant avec l'avant-guerre}

La place du cinéma dans la politique internationale française au lendemain de la guerre est tributaire du rôle qui lui était attribué avant la guerre et du système de diffusion qui s'est mis en place dans les années 1930. Le phénomène cinématographique en Roumanie se résume très vite, après l'apparition de l'appareil de projection en 1896 dans ce pays, aux importations, tandis que la production locale restait à un stade artisanal, fruit d'improvisations sans véritables perspectives de stabilité et de continuité ${ }^{10}$. Ainsi la Roumanie devint-elle une terre de conquête

\footnotetext{
9. Albert Salon, op. cit., pp 5-6.

${ }^{10}$. Un observateur de la production cinématographique roumaine précise en 1925 : «Parler de la Roumanie du point de vue cinématographique, c'est ne parler qu'au point de vue du débouché que les grandes industries cinématographiques étrangères ont trouvé dans notre pays »: M. Beilis, "Roumanie », Cinémagazine, $\mathrm{n}^{\circ}$ 7, 13 février 1925 , p. 324.
} 
pour les grandes maisons internationales américaines, françaises et allemandes dont les films couvrent 98,42\% dudit marché en $1933^{11}$.

$\mathrm{Au}$ lendemain de la guerre, une dynamique similaire semble s'imposer sur le marché du film, car parfois les mêmes acteurs et, souvent, les mêmes pratiques de distribution reprennent leur place ou s'efforcent de le faire. Cette démarche est favorisée d'une part par la reprise, assez rapide comparée au cas américain et britannique, des relations diplomatiques, et d'autre part par l'accord commercial franco-roumain signé en juillet 1946. Celui-ci prévoit l'importation en France de matières premières roumaines, surtout des produits issus de l'agriculture et des produits pétroliers, et l'exportation de multiples produits finis français, dont les produits cinématographiques ( films spectaculaires, documentaires et d'actualités $»^{12}$ ). Les maisons françaises s'appuient sur des distributeurs locaux, intermédiaires de longue date comme Marcel Bărbuţă, chargé de la distribution des films français en Roumanie, Bulgarie, Hongrie, Yougoslavie, et partenaire de confiance, semble-t-il, de la Société nouvelle des établissements Gaumont qui lui confie systématiquement ses films ${ }^{13}$. De même, la société roumaine Memento devient dès 1945 le partenaire privilégié de la société Zénith jusqu'à sa nationalisation en novembre $1948^{14}$. Certes, dans le contexte de la reconstruction d'après-guerre, certaines démarches n'ont plus la même efficacité et certains entrepreneurs, découragés, abandonnent leurs affaires ${ }^{15}$. Toutefois, en dépit des changements de personnes, le commerce cinématographique se maintient.

En parallèle, une nouvelle vision du cinéma et de son rôle social émerge discrètement dans l'espace public. Victor Iliu, réalisateur et conseiller technique à l'Office national de la cinématographie entre 1945 et 1949, artiste affilié au mouvement communiste avant la guerre, préconise dès 1945, dans un article du journal communiste Scînteia, la fin progressive de ces sociétés intermédiaires :

[...] dans un régime de coopératives ou de production et diffusion officielle du film, cette catégorie de commerçants-intermédiaires devra disparaître. Le film ne doit plus être une marchandise, ou ne devrait plus être une marchandise ordinaire ${ }^{16}$.

Portant un discours qui peut être interprété comme prophétique au vu de l'évolution des années suivantes, l'article de Victor Iliu reflète surtout les aspirations d'un intellectuel communiste enthousiaste à l'idée d'une société nouvelle et souhaitant une restructuration générale du cinéma. Cette vision reste plutôt marginale parmi les prises de position officielles des communistes, la plupart des articles consacrés au phénomène cinématographique se limitant à tenir la chronique des films. Bien que le discours prônant le cinéma progressiste d'inspiration

11. Georgiana Mirela Medrea, Les Relations culturelles franco-roumaines dans l'entre-deux-guerres, thèse de doctorat, Université Paris Sorbonne-Paris 4, 2010, p. 414.

12. Archives Nationales Historiques Centrales, Bucarest (ci-après: ANIC), Fonds Ministerul comerţului exterior, 1/1947, «Engagement entre le gouvernement roumains et le gouvernement français », 3 juillet 1946, ff. 4-6.

13. Archives du ministère roumain des Affaires Extérieures, Bucarest (ci-après : AMRAE), Fonds Franţa, 217. Culturale : Activitatea de relaţii culturale a Oficiului Paris : 1946 (ci-après : Franţa, 217), lettre de la Société nouvelle des établissements Gaumont à la légation royale de Roumanie à Paris, 12 juillet 1946.

14. AMRAE, Franţa, 217, tél. 23 juin 1945.

15. C'est le cas de M. Barbuţă qui cède en juillet 1946 ses droits d'exploitation sur les huit films français que Gaumont lui a confiés. AMRAE, Fonds Paris. Culturale, vol.39 (ci-après Paris 39), 1948-1952, lettre de la Société Nouvelle des Établissements Gaumont à la légation roumaine, 12 juillet 1946. Notes manuscrites rajoutées postérieurement.

16. Victor Iliu, « Problemele cinematografiei româneşti. Pentru un sindicat unic al cinematografiştilor » (Les problèmes du cinéma roumain. Pour un syndicat unique des professionnels du cinéma), Scînteia, n ${ }^{\circ} 142,17$ février 1945 , p. 2. 
communiste soit très présent au sein des réunions internes du parti ${ }^{17}$, il ne pénètre dans l'espace public qu'après septembre 1947 et surtout à partir de 1948. Les communistes roumains agissent ainsi vraisemblablement par prudence : face aux négociations internationales laborieuses entre les Soviétiques et les Anglo-Américains, ils préfèrent mettre en sourdine les projets de restructuration fondamentale du milieu cinématographique.

\section{La stagnation du film français en 1945 : les circonstances d'un faux départ}

Malgré l'avantage dont la France semble bénéficier en 1945 dans ses rapports politiques avec la Roumanie et en dépit de la situation privilégiée du film français au lendemain de la guerre, la reprise des relations cinématographiques est lente ${ }^{18}$. Quatre facteurs contribuent alors à empêcher la France de profiter de ces atouts : l'état de l'économie après-guerre, la concurrence américaine, la campagne d'épuration du milieu cinématographique français et l'émergence du pouvoir soviétique.

La guerre fait en effet sentir ses effets sur l'économie roumaine : inflation galopante, nécessité de reconstruire les réseaux de communication et de transport, les infrastructures ${ }^{19}$. Cette situation affecte profondément le commerce cinématographique : de nombreuses salles ont été bombardées, les propriétaires des salles ruinés ; le bas prix des billets et la lourdeur des taxes sur les films d'importation entraînent des coûts d'exploitation très bas ${ }^{20}$. Si ces conditions sont les mêmes pour tous les importateurs, les Français, fragilisés, semblent, à la différence des Américains, moins disposés à accepter ces conditions de vente défavorables. Le cinéma américain, aidé par le gouvernement des États-Unis et la politique cinématographique que conduit en Europe de l'Est Eric Johnston, le président de Motion Picture Association of America (MPAA), connaît un envol spectaculaire ${ }^{21}$. Malgré les tensions diplomatiques résultant notamment du refus des gouvernements britannique et américain de reconnaître le gouvernement roumain, les relations commerciales, et en particulier cinématographiques ne sont pas véritablement entravées par les Soviétiques. En Roumanie, le film américain écrase la concurrence dès octobre 1945, grâce à la distribution effectuée par la société Warner Bros et son représentant, Armand Pauker ${ }^{22}$ (sans lien de famille, a priori, avec les leaders communistes

17. Cristian Vasile, «Cinematografia românească în perioada de tranziţie de la epoca veche la realismul socialist : 1945-1949» (Le cinéma roumain dans la période de transition de l'ancienne époque au réalisme socialiste : 1945-1949) Arhivele Securităţii, vol. 4, Bucarest, editura Enciclopedică, pp. 314-326.

18. L'alliance germano-roumaine durant la Seconde Guerre mondiale conduit ou oblige les autorités roumaines à évincer les films américains des écrans et à favoriser les films allemands (Barbara Nelson, « The HollywoodGerman Cinematic Struggle for the Romanian Market, 1938-1945 », Historical Journal of Film, Radio and Television, vol. 29, 3 septembre 2009, pp. 295-319) et italiens (Ion I. Cantacuzino, Intâlniri cu cinematograful. Amintiri (Rencontres avec le cinéma. Souvenirs) Bucarest, édition Alo, 1997, pp. 141-185). Dans ces circonstances, la société allemande Continental fait appel aux productions françaises qui se retrouvent, de fait, dans la situation d'être plus largement distribuées qu'avant 1939 : Archives du ministère français des Affaires étrangères, La Courneuve (ci-après : AMAE-La Courneuve), 201QO/38, lettre de la légation de France à Bucarest au Département, 19 décembre 1947, f. 164.

19. Bogdan Murgescu, România şi Europa. Acumularea decalajelor economice (1500-2010) (La Roumanie et l'Europe. L'accumulation des décalages économiques (1500-2010)) Bucarest, Polirom, 2010, pp. 332-333.

20. AMAE-La Courneuve, 201QO/38, lettre de la légation de France à Bucarest au Département, 19 décembre 1947, f. 165.

21. Jindriska Blahova, « A Merry Twinkle in Stalin’s Eye: Eric Johnston, Hollywood, and Eastern Europe », Film History, vol. 22, 2010, pp. 347-359.

22. «Un bucureştean la Hollywood»(Un bucarestois à Hollywood). Cinema: Revistă cinematografică bilunară, $\mathrm{n}^{\circ}$ 695-696, 16-31 décembre 1945. 
Marcel et Ana Pauker) et plus tard par la société Arta film ${ }^{23}$. Ce retour en force des productions américaines, qualifié avec enthousiasme d' " offensive » ou d' " invasion » par la revue Cinema, est également attendu et salué par le public roumain ${ }^{24}$. Dans le même temps, la campagne d'épuration du cinéma français menée par le Comité de libération du cinéma ralentit le rythme des exportations, l'attitude des réalisateurs pendant l'Occupation étant soumise à des investigations qui, par ricochet, touchent leurs films ${ }^{25}$. Cela entrave sérieusement la reprise des exportations du film français dans l'immédiat après-guerre. Enfin, apparaît sur la scène politique roumaine un nouvel acteur international et un concurrent redoutable dans tous les domaines : l'Union Soviétique. Le cinéma devient rapidement une priorité pour l'URSS qui, bénéficiant du relais des communistes roumains au pouvoir, devient bientôt le principal obstacle devant la diffusion des films occidentaux.

Dans ces conditions, la distribution des films français dans les salles de cinéma roumaines repose, dans un premier temps, sur les films fournis par la Continental pendant la guerre et sur le stock d'avant 1940, en grande partie des films de "second ordre », selon le chargé d'affaires ${ }^{26}$. En effet, si l'on parcourt les programmes des salles bucarestoises en 1945, on s'aperçoit que le marché est dominé par des films anciens et pas toujours les plus prestigieux, à l'exception de celui d'Henri Georges Clouzot, Le Corbeau (1943) : L'Agonie des aigles de Roger Richebé (1933), Flofloche de Gaston Roudès (1934) ${ }^{27}$, Le Collier de chanvre de Léon Mathot (1940), et Deuxième bureau contre Kommandantur de René Jayet et Robert Bibal $(1937)^{28}$, Rapt de Dimitri Kirsanoff (1934), Au son des guitares de Pierre-Jean Ducis $(1936)^{29}$. L'absence de films français nouveaux est ressentie vivement par le public roumain, ce dont témoignent la revue Cinema, mais aussi les représentants de la Roumanie à Paris.

\section{La société Filmul popular : un atout pour la France}

Les rapports de force s'équilibrent dans le marché de film en Roumanie avec la création en novembre 1945 d'une société bénéficiant de l'appui du Parti communiste roumain, Filmul Popular (Le Film populaire). Comment interpréter l'immixtion du Parti dans le marché cinématographique? Cette société annonce-t-elle une mainmise politique des communistes, soutenus par les Soviétiques, sur le cinéma? Et comment comprendre la dynamique des liens qu'elle établit avec la France en 1946 et 1947 ?

Le groupe fondateur de la société anonyme Filmul popular comprend des journalistes, des critiques, des artistes plastiques et des techniciens parmi lesquels certains se situent politiquement à gauche (communistes, socialistes ou compagnons de route) tandis que d'autres possèdent une expérience de gestion d'affaires cinématographiques ${ }^{30}$. Cette composition, au-

\footnotetext{
23. Bogdan Barbu, « Hollywood Movies, American Music and Cultural Policies behind the Iron Curtain. Case Study: Cold War Romania, 1945-1971 », in S. Jakelic, J. Varsoke (eds.) Crossing Boundaries: From Syria to Slovakia, Vienna, IWM Junior Visiting Fellows' Conferences, vol. 14, 2003.

24. Cinema: Revistă cinematografică bilunară, n 674, 6-20 juin 1945.

25. Jean-Pierre Bertin-Maghit, Le Cinéma sous l'Occupation. Le monde du cinéma français de 1940 à 1946, Paris, Olivier Orban, 1989, pp. 191-216.

26. AMAE-La Courneuve, 201QO/38, lettre de la légation de France à Bucarest au Département, 19 décembre 1947, f. 165.

27. Cinema: Revistă cinematografică bilunară, $\mathrm{n}^{\circ}$ 665, 15-31 janvier 1945.

${ }^{28}$. Ibid., $\mathrm{n}^{\circ} 667,15-28$ février 1945.

${ }^{29}$. Ibid., $\mathrm{n}^{\circ} 672,1^{\mathrm{er}}-15$ mai 1945.

30. Selon Monitorul oficial, 19 novembre 1945, ce groupe est formé de : Marcel Mocanu (comptable), Camil Ressu (peintre), Zoe Băicoianu (sculpteur), D.I. Suchianu (critique de cinéma), Maria Voluntaru (actrice), Isidor Simsa (chef d'atelier, gestionnaire de laboratoire), Aurel Pârvu (ingénieur), Mircea Nădejde (muséographe/historien de l'art) et Mircea Bârsan. Voir aussi la base de données Analiza dosarelor comuniştilor ilegaliști en ligne : http://www.andco.ro/aplicatie (date de consultation: 10 janvier 2015).
} 
delà des affinités politiques des membres, montre surtout le statut du cinéma en Roumanie. Celui-ci n'est pas organisé en une véritable corporation mais plutôt une activité au croisement des métiers à la fois artistiques (théâtre, peinture, sculpture, littérature), techniques et commerciaux.

Les premiers résultats de Filmul popular sont rendus publics en avril 1946 lorsque la revue Cinema annonce en grande pompe l'arrivée sur les écrans roumains des dernières productions françaises - plus précisément celle de films réalisés pendant la guerre et après $1944^{31}$. La revue cite uniquement trois titres, considérés comme les plus représentatifs : Après Mein Kampf mes crimes, documentaire-fiction de Jean-Jacques Valjean, pseudonyme d'Alexandre Ryder (1940), Le Colonel Chabert de René Le Hénaff (1943), François Villon d'André Zwoboda (1945). Mais tout au long de l'année 1946 et jusqu'à la fin de 1947, la liste des films français s'allonge : Le Valet maître de Paul Mesnier (1941), La Femme que j'ai le plus aimée de Robert Vernay (1942), Les Clandestins d'André Chotin (1946), Un seul amour de Pierre Blanchar (1943), L'Éternel retour de Jean Delannoy (1943), Étrange destin de Louis Cuny (1946), Le Cavalier noir de Gilles Grangier (1945), Les Enfants du paradis de Marcel Carné (1945), La Symphonie fantastique de Christian-Jaque (1942), La Symphonie pastorale de Jean Delannoy (1946), Le Bataillon du ciel d'Alexandre Esway (1945), etc.

À en juger d'après ces titres, il s'agit de types de production susceptibles de faire l'objet d'accords commerciaux avec la Roumanie : films interdits pendant l'Occupation et diffusés à la Libération, films réalisés pendant l'Occupation mais autorisés à la diffusion après l'épuration et enfin, films réalisés après la Libération. Néanmoins, aucun d'entre eux ne porte l'empreinte du Parti communiste français (PCF), pourtant fortement impliqué dans la production et la diffusion cinématographiques après la guerre ${ }^{32}$. Ni les réalisateurs de ces films, ni leurs scénarios ne portent l'empreinte communiste. Il est vrai que le PCF ne possède pas de structures d'exportation propres et que son influence dans cette branche de l'industrie cinématographique est minime, ce qui pourrait expliquer la faible présence et réputation des films réalisés dans le sillage du PCF sur les marchés internationaux. D'autre part, la démarche de Filmul popular, malgré le soutien financier du PCR, n'est pas politique ; elle ne sélectionne pas les sujets selon un objectif idéologique et son but semble être de nouer des accords commerciaux avec des sociétés de production françaises et d'importer des films français.

Les autorités françaises, qui considèrent Filmul popular comme une société inconnue sur le plan international et politiquement connotée, n'en sont pas moins méfiantes. C'est peut-être la raison pour laquelle Filmul popular met plusieurs mois à gagner la confiance des distributeurs français. L'intervention de la diplomatie culturelle roumaine, recommandant par voie officielle la société à la Direction générale de la cinématographie du ministère français de l'Information, joue un rôle essentiel dans son changement d'image ${ }^{33}$. Celle-ci bénéficie également de subventions officielles du PCR et de crédits en devises qui lui permettent d'acheter de nouveaux films français, gagnant ainsi en crédibilité auprès de ses interlocuteurs ${ }^{34}$. Si méfiance il y a en

31. «Au sosit noile filme franceze » (Les nouveaux films français sont arrivés), Cinema: Revistă cinematografică bilunară, $\mathrm{n}^{\circ}$ 709-710, 16-30 avril 1946.

32. Pauline Gallinari, Les Communistes et le cinéma : France, de la Libération aux années 60,

Rennes, Presses universitaires de Rennes, 2015. L'auteure montre que le PCF possède certaines sociétés de production et que des réalisateurs français communistes et des compagnons de route exercent une influence très forte sur les syndicats, les organismes et les politiques publiques du cinéma à la Libération.

33. AMRAE, Paris 39, 1948-1952, lettre de la légation roumaine de Paris à la Direction générale de la cinématographie du ministère français de l'Information, $1^{\text {er }}$ juin 1946. "La société anonyme roumaine Filmul popular est connue comme une maison importante, de toute confiance, s'occupant de la diffusion des films, de leur production et contrôlant un circuit de plus de 70 cinématographes. La légation recommande chaleureusement cette maison et serait désireuse que soient reprises les relations cinématographiques entre ces deux pays amis [...] ».

${ }^{34}$. AMAE-La Courneuve, 201QO/38, lettre de la légation de France à Bucarest au Département, $1^{\text {er }}$ août 1947, f. 88 . 
1946, il n'y en a plus trace une année plus tard : en août 1947, Filmul popular est recommandé par la légation française elle-même comme un partenaire indispensable, le premier conseiller commercial assurant qu'elle est la « mieux placée pour diffuser des films cinématographiques français en Roumanie $\gg{ }^{35}$.

L'apparition de cette société bouleverse en quelque sorte les courants d'importation et d'exploitation des films car, profitant de l'appui du Parti communiste et détenant les meilleures salles, elle parvient à contrôler la plus grande partie du marché et se retrouve nettement privilégiée par rapport aux autres sociétés privées. Le cinéma français en est le principal bénéficiaire. Cette préférence trouve probablement son moteur dans les liens personnels de certains membres de la société avec la France ${ }^{36}$, mais aussi dans les efforts intenses du consul de Roumanie à Paris, Herant Torossian, insistant sur le manque de films français en Roumanie, pour promouvoir Filmul popular auprès des autorités françaises ${ }^{37}$. Ainsi, de 1946 au printemps/été 1947, la société tiret-elle profit des liens traditionnels que certaines élites roumaines entretiennent avec des partenaires français.

Cette situation favorable se détériore néanmoins dans la deuxième moitié de l'année 1947, où les tensions internationales ont raison du commerce cinématographique avec les pays occidentaux, y compris avec la France. Les acquisitions réalisées en France après août 1947 subissent les mêmes entraves à la diffusion que les films proposés par les sociétés commerciales traditionnelles ${ }^{38}$. D'après la légation, un comité de validation refuse alors les films sélectionnés par Filmul popular, par exemple Les Bataillons du ciel d'Alexandre Esway (1947) et La Septième porte d'André Zwoboda (1947). Par ailleurs, les meilleures salles de la capitale ne sont plus disponibles pour la projection des films français. L'autonomie dont jouissait Filmul popular ne correspond plus aux exigences du PCR ; par conséquent, elle disparait en octobre 1948. Créée en juin 1948, la société d'État Cinexfilm, rattachée au ministère des Arts et des Informations, la remplace en reprenant en partie ses attributions et ses acquisitions ${ }^{39}$. Cinexfilm est bâtie sur de nouvelles bases : subventionnée par l'État, elle est également mieux contrôlée. Filmul popular a donc représenté le premier pas vers la nationalisation du domaine cinématographique, laquelle est effective en novembre 1948.

\section{LES TENSIONS INTERNATIONALES ET LEUR IMPACT SUR LES RELATIONS CINÉMATOGRAPHIQUES : LES NOUVELLES STRATÉGIES ROUMAINES}

\section{La nouvelle politique cinématographique roumaine et ses effets sur l'importation}

\footnotetext{
35. Ibid.

36. Parmi les membres ayant des liens avec la France, citons d'abord D.I.Suchianu, critique de cinéma. Il obtient son doctorat en droit et science politiques à Paris. Entre 1938 et 1940, il est à la tête de la Direction de la Cinématographie et s'occupe, pendant la guerre, de la diffusion des films français en Roumanie : Bujor T. Rîpeanu, Cinematografiştii (Les cinématographistes) Bucarest, Editura Meronia, p. 540. Citons ensuite Alexandru Eskenazy qui devient directeur commercial de la société en janvier 1947, à la place de Marcel Mocanu. Il est décrit dans un document du Parti (non signé) dans les termes suivants : " anciennement secrétaire de cinématographe, [...] Roumain ténébreux, dupe le Parti. Tous les ans il est envoyé à Paris pour acheter des films et avec son frère de là-bas fait ses propres affaires et ensuite, avec quelques films français, revient triomphant. C'est lui qu'il faut remercier pour l'état du film roumain, le plus faible du monde »: ANIC, Fonds CC al PCR. Secţia Cancelarie, 139/1948, 19 décembre 1947, f. 23.

37. AMRAE, Paris 39, 1948-1952, lettre de la légation roumaine de Paris à la Direction générale de la cinématographie du ministère français de l'Information, $1^{\mathrm{er}}$ juin 1946.

${ }^{38}$. AMAE-La Courneuve, 201QO/38, lettre de la légation de France à Bucarest au Département, 19 décembre 1947, ff. 165-166.

39. ANIC, Fonds Ministerul Artelor şi informaţiilor, 483/1948.
} 
Il est difficile de situer avec précision le point de départ de la dégradation des relations cinématographiques avec la France, alors qu'une succession d'évènements politiques intérieurs et internationaux accentuent les tensions entre les deux anciens alliés, l'URSS et les États-Unis. Pourtant, les premiers mois de l'année 1947 sont de bon augure pour la reprise du commerce cinématographique. L'organisation en Roumanie, en novembre 1946, des premières élections après la guerre, condition imposée par les alliés anglo-américains pour la poursuite de leurs négociations avec l'URSS, est censée apporter un certain apaisement. De fait, Washington et Londres acceptent de signer le traité de paix avec la Roumanie en janvier et février 1947. Pour le milieu cinématographique, le début de l'année promet la relance du commerce, dont on prévoit cependant que le grand gagnant sera le cinéma américain ${ }^{40}$. Par ricochet, le film français risque donc de subir une concurrence implacable, comme dans l'entre-deux-guerres. Pourtant, l'escalade du printemps 1947 avec l'affirmation de la doctrine Truman, l'annonce du plan Marshall et la création du Kominform par les Soviétiques en septembre, fait basculer le monde dans une nouvelle logique idéologique de défense des valeurs, et non plus dans celle de la rationalité géopolitique qui avait prévalu jusque-là ${ }^{41}$. Quels bouleversements en résulte-t-il dans le paysage cinématographique roumain, et comment les projets commerciaux de chacun s'en trouvent-ils influencés?

À partir de l'automne 1947, dans le nouveau contexte de guerre idéologique, deux éléments contribuent à changer le paysage cinématographique en Roumanie : l'assaut livré par le film soviétique qui conduit petit à petit au monopole et à l'instauration d'une censure sur le contenu et la provenance des films. La société mixte roumano-soviétique Sovromfilm, créée en 1946, intensifie son activité dans la deuxième moitié de l'année 1947 et en $1948^{42}$; sa mission, qui est de distribuer et de familiariser le public roumain avec le film soviétique, reçoit tout le soutien des autorités roumaines ${ }^{43}$. Les autorités françaises à Bucarest rendent compte de la mainmise exercée par le cinéma soviétique sur les salles et des efforts des autorités roumaines pour leur faciliter la tâche ${ }^{44}$. Très souvent cette emprise fait suite à des actions abusives qui bafouent les réglementations internationales d'après-guerre. Les films soviétiques bénéficient ainsi des meilleures salles de cinéma de la capitale, parviennent souvent à faire déprogrammer les autres films au bon gré des autorités communistes et bénéficient d'une réduction d'impôt de $50 \%$, ce qui constitue une violation des stipulations des traités de paix ${ }^{45}$. La disparition pratiquement des films français sur les écrans entraîne celle des " actualités ", un préjudice particulièrement ressenti à Paris. Déloyale, la concurrence soviétique est décidément redoutable ; elle est écrasante pour les films français et, plus généralement, occidentaux.

\footnotetext{
${ }^{40}$. La revue Cinema annonce l'arrivage de 140 films américains pour l'année 1947. « Incepe ofensiva filmului american » (L'offensive du film américain commence), Cinema. Revistă cinematografică bilunară, $\mathrm{n}^{\circ}$ 741-742, $1^{\text {er }}-15$ février 1947.

41. René Girault, Robert Frank, Jacques Thobie, La Loi des géants. 1941-1964, t. 3, Paris, éditions Payot et Rivages, 2005, p. 160.

42. Les circonstances et le moment de sa création ne sont pas très précis. Selon les documents du Parti datant de la dissolution de Sovromfilm, la société aurait été créée en 1947 : ANIC, Fonds CC al PCR Secţia Propagandă şi Agitaţie, 71/1951, p. 6. Mais le dernier numéro spécial de la revue Cinema de décembre 1946 est présenté comme étant édité par Sovromfilm.

43. L'action cinématographique soviétique en direction de la Roumanie est un chapitre essentiel de l'histoire du cinéma roumain qui attend d'être écrite Quelques éléments épars existent déjà cependant : Aurelia Vasile, Le Cinéma roumain dans la période communiste. Représentations de l'histoire nationale, Bucarest, Editura Universităţii din Bucureşti, 2011, pp. 62-72 ; Cristian Vasile, Literatura şi artele în România comunistă 19481953 (La littérature et les arts dans la Roumanie communiste 1948-1953) Bucarest, Humanitas, 2010, pp. 216222.

44. AMAE-La Courneuve, 201QO/38, lettre de la légation de France à Bucarest au Département, 19 décembre 1947, f. 166.

45. Ibid., f. 167.
} 
L'autre obstacle qui se dresse devant l'action cinématographique française est la nouvelle politique de sélection des films importés. Elle se traduit par la promotion des films dits " progressistes » et l'instauration d'une censure du même ordre sur leur contenu. Si la promotion des films militants soutenant la collectivisation, la justice sociale et dénonçant les pratiques bourgeoises et l'impérialisme a toujours été une priorité de la propagande du Parti communiste, ces critères sont appliqués plus strictement après la chute de la monarchie et la prise exclusive du pouvoir par les communistes en décembre 1947. La question du «fond progressiste » des films devient certainement un leitmotiv des discours des responsables de la cinématographie ${ }^{46}$.

Ces mesures touchant à l'importation de films étrangers sont accompagnées d'un projet phare dans le domaine de la production, à l'état embryonnaire en 1948. Il s'agit de construire un centre de production cinématographique à Buftea, équipé des derniers appareils de tournage, de sonorisation et de traitement des pellicules ${ }^{47}$. Ce projet, conçu par des architectes soviétiques et mis en œuvre par des techniciens roumains, change les perspectives, le cinéma n'étant plus envisagé comme une marchandise étrangère, mais comme un produit national, le fruit d'une industrie roumaine potentielle. Ces trois éléments cumulés constituent les bases d'une politique cinématographique et vont contribuer de manière substantielle à la disparition du film américain et au déclin du film français en Roumanie.

\section{La diplomatie culturelle in situ : contraintes et opportunités}

Si du point de vue politique, la France n'est plus en mesure de miser sur sa neutralité dans les relations avec la Roumanie, si l'heure est au « réalisme nécessaire », il nous parait essentiel de mettre en évidence les marges de manœuvre qu'offrent aux acteurs publiques et privés, pour assurer la continuité de la présence française en Roumanie, les valeurs progressistes promues par la diplomatie française et le cinéma produit dans le sillage du PCF. Promu dès la fin de la guerre, le discours français autour du triptyque « la France résistante, la France progressiste, la France en reconstruction » est mobilisé en Roumanie à partir surtout de l'automne $1947^{48}$. Visiblement, au moment où sa présence culturelle en Roumanie est menacée, la diplomatie française à Bucarest puise dans ces valeurs progressistes, espérant que cette stratégie lui permettra de trouver un terrain commun avec les valeurs communistes roumaines. Compte tenu des fortes barrières idéologiques imposées par les autorités du cinéma pour la sélection des films, cette stratégie semble avoir été fructueuse.

La légation française a repéré des facteurs qui l'encouragent à lutter : le faible succès du cinéma soviétique auprès des spectateurs, le rejet de la langue russe par la population et le nombre insuffisant de productions soviétiques pour fournir la totalité des salles de cinéma du pays $^{49}$. Exacte en partie, cette interprétation de la réception des films par les spectateurs roumains doit être nuancée. Elle s'appuie sur des constats faits par la légation en milieu urbain, là où le cinéma occupe une place importante dans les pratiques culturelles. Or, la majorité de la population roumaine vit en milieu rural où le cinéma parvient sous la forme de films soviétiques et par le biais de réseaux de diffusion mis en place par les communistes. Si les spectateurs

\footnotetext{
46. ANIC, fonds Ministerul Artelor şi informatiilor, 340/1948, f.2.

47. Ce projet murit en décembre 1948 lorsque l'architecte soviétique Gheorghe Lavrentievici est invité en Roumanie : ANIC, Fonds CC al PCR, Secţia Propagandă şi agitaţie, 87/1949, ff. 14-15.

48. Annie Guénard, « De la reconstruction à l'éviction. Entre 1944 et 1949, une politique culturelle française en Europe centrale et orientale confrontée à l'organisation du Bloc communiste », Matériaux pour l'histoire de notre temps, $\mathrm{n}^{\circ} 36,1994$, p. 23.

49. AMAE-La Courneuve, 201QO/38, lettre de la légation de France à Bucarest au Département, 19 décembre 1947, f. 167.
} 
citadins peuvent en effet être très peu réceptifs aux films et à la langue russe, les spectateurs des campagnes, eux, découvrent le cinéma au travers des productions soviétiques.

Aussi étroite soit-elle, cette brèche que constitue, semble-t-il, l'espace urbain doit être exploitée selon les diplomates français, d'autant que les autres films occidentaux, notamment américains et anglais, souffrent davantage des changements intervenus dans la deuxième moitié de 1947. D'après la légation, le vide créé par le manque d'approvisionnement sera automatiquement comblé par le film français, premier choix des autorités roumaines ${ }^{50}$. De fait, il s'avère impossible de remplir le plan d'importation roumain avec les seules productions de l'URSS et de ses satellites ${ }^{51}$, ce qui conduit les autorités roumaines à chercher des films "progressistes» ailleurs. Ainsi, la société Cinexfilm envisage-t-elle en octobre 1948 d'importer dix films français ainsi que cinq films italiens, cinq hongrois, deux polonais, cinq suédois et «américains progressistes avec Charlie Chaplin » ${ }^{52}$. De plus, le ministère des Arts et de l'Information roumain ainsi que le département du cinéma appuient cette initiative, s'adressant en décembre 1948 à la légation à Paris afin d'obtenir une liste de films français « progressistes », susceptibles de faire l'objet d'une importation en Roumanie. Dans ce but, la légation fait appel à des spécialistes français, notamment à Léon Moussinac, directeur de l'Institut de hautes études cinématographiques (IDHEC) et militant communiste connu ${ }^{53}$. Les initiatives de Cinexfilm ou celle de la diplomatie roumaine auprès de Moussinac n'aboutissent pas à cause de la dénonciation des accords culturels franco-roumains de novembre 1948, mais cela ne dissuade pas les autorités roumaines de se diriger, dans le contexte d'une forte demande de films «progressistes » vers les productions françaises. Alors que tout produit occidental associé à l'impérialisme est rejeté, le film français est le seul qui continue d'être présent sur les écrans roumains jusqu'au début de l'année 1949.

Les dysfonctionnements de la diffusion et du réseau d'exploitation cinématographique contribuent aussi de façon non négligeable à la programmation des films français, surtout dans la première phase de mise en œuvre de critères stricts de sélection et de diffusion des films. Il s'agit d'un phénomène propre à toute période de transformation sociale et institutionnelle : la confusion, les malentendus, le manque de coordination dénaturent les directives officielles. C'est ce qu'Antonela Capelle-Pogăcean et Nadège Ragaru, évoquant la programmation à Gorna Džumaja du film Les Trois valses de Ludwig Berger (1938), qualifient de «jeu des coïncidences, des anticipations erronées et des ajustements imparfaits à des règles changeantes affectant l'offre filmique $»^{54}$. Un rapport sur le fonctionnement d'un cinéma de province rend également compte de cet état de fait ${ }^{55}$.

Les démarches des autorités centrales de Bucarest pour favoriser la diffusion des films soviétiques se heurtent aux difficultés d'organisation de la société Sovromfilm et à l'incapacité des autorités locales de coordonner les opérations. Très souvent les copies des films sont de mauvaise qualité, impossibles à utiliser; le transport des films d'un cinéma à l'autre se heurte à des déficiences organisationnelles et les responsables des salles de cinéma se retrouvent à plusieurs reprises sans films à projeter. Certaines autorités locales, comme celles de la commune de Fălciu, font appel à la société Cinexfilm qui possède des films autres que soviétiques, " afin de ne pas laisser ce cinéma sans films ${ }^{56}$ et cela, sans se préoccuper du fond

\footnotetext{
${ }^{50}$. Ibid., f. 168.

51. Le plan fixait 60-70 films pour la période 1948-1949 avec 35 films soviétiques et 4 hongrois. AMAE-La Courneuve201QO/38, lettre de la légation de France à Bucarest au Département, 30 septembre 1948.

52 . ANIC, fonds Ministerul Artelor şi informatiilor, 333/1948, f.4.

53. AMRAE, Paris 39, 1948-1952, lettre de la légation roumaine à Paris (signée Theodosia Graur) au ministère des Arts et de l'Information, 2 janvier 1948.

54. Antonela Capelle-Pogăcean, Nadège Ragaru, « La culture habitée aux frontières du socialisme (Gorna Džumaja, 1944-1948) ", Annales. Histoire, Sciences Sociales n 2, 2013, p. 410.

55. ANIC, fonds Ministerul Artelor şi informatiilor, 340/1948, ff. 58-59.

56. Ibid., f. 58.
} 
progressiste des œuvres. C'est ainsi qu'en mai, juin, juillet 1948, sont programmés à Fălciu six films soviétiques, huit films français, deux films italiens et un film américain. Les films français proviennent vraisemblablement de l'ancien dépôt de Cinexfilm, héritier de Filmul popular ${ }^{57}$. Leur diffusion ne semble être conditionnée ni par leur date de sortie, ni par leur contenu progressiste. C'est seulement après leur projection que les responsables locaux réalisent combien certains de ces films détonent avec l'idéologie politique, la morale et même les goûts du temps. Ce type d' " accident», qui devait être assez répandu en 1948, au moment où les nouvelles structures et politiques se mettent en place, montre précisément le manque de coordination, sinon de désordre, qui pouvait perturber le processus de popularisation du cinéma progressiste, par ailleurs si bien préparé au «centre ». Bien que mineures au regard de leur impact sur l'évolution du marché de film, ces incohérences profitent à court terme au film français, sans intervention aucune des diplomates ${ }^{58}$.

\section{La légation française, un intermédiaire pour la circulation des films en Roumanie (1945-1951)}

$\mathrm{Si}$, de manière générale, la pénétration du film français en Roumanie se fait jusqu'en 1947 par le biais de sociétés privées qui négocient directement les prix, la diplomatie française commence à jouer un rôle important dans le commerce cinématographique à partir surtout de l'automne 1947. Elle intervient soit pour favoriser les échanges entre les deux partenaires, soit pour régler des litiges. Mais, loin de promouvoir une politique cohérente ou coordonnée par Paris, ses initiatives illustrent l'engagement spécifique et ponctuel des représentants français en Roumanie dans leur combat pour préserver toute forme de culture susceptible de contribuer au rayonnement français.

La légation devient un acteur essentiel pour la présence cinématographique française en Roumanie, lorsque les anciennes sociétés de location s'effacent peu à peu en devant le système de distribution nationalisé et les formes plus rigides prises par la censure. Ayant comme objectif de sauvegarder des espaces et des formes de diffusion, même limitées, pour le cinéma français, la légation de Bucarest use de tous les moyens à sa disposition. D'abord, elle demande au Quai d'Orsay d'intervenir au sujet d'un problème financier qui se posait dès les années 1930 : il s'agit " obtenir des producteurs français une réduction substantielle de leurs conditions de prix » et qu'ils renoncent à la politique du prix ferme (ou forfaitaire ?) pour une « formule plus souple de participation aux recettes ». Ensuite, elle encourage le transport des œuvres par la valise diplomatique et leur projection à l'Institut français de Bucarest afin de limiter les risques de rejet par la censure ${ }^{59}$. Enfin, la légation s'attache à identifier les critères de la censure de façon à pouvoir conseiller les exportateurs français sur les sujets à privilégier ou à éliminer, comme :

[...] les films qui rappellent l'impérialisme (sujets coloniaux, allusion à l'armée, à la marine), ceux qui évoquent une atmosphère de luxe et présente la vie sous un aspect irréel, les films antimarxistes, dont le sujet est contraire à la science ou au matérialisme historique, les aventures de résistance dans lesquelles il est fait allusion au Comité français de Londres, les films retraçant un épisode quelconque de l'histoire où la réaction a triomphé, ou évoquant un complot ou une conspiration ${ }^{60}$.

57. Il s'agit des films suivants : Pierre et Jean d'André Cayatte (1943), La symphonie fantastique de ChristianJaque (1942), L'éternel retour de Jean Delannoy (1943), Feu sacré de Maurice Cloche (1942), Les visiteurs du soir de Marcel Carné (1942), Boule de Suif de Christian-Jaque (1945), Sylvie et le fantôme de Claude Autant-Lara (1946), La Symphonie pastorale de Jean Delannoy (1946).

58. Gail Kligman, Katherine Verdery, Peasants under Siege: The Collectivization of Romanian Agriculture, 1949-1962, Princeton University Press, 2011, pp. 5-7 : ces incohérences participent de ce que ces auteurs appellent la formation de l'État-Parti.

59. AMAE-La Courneuve, 201QO/38, lettre de la légation de France à Bucarest au Département, 19 décembre 1947, f. 168.

${ }^{60}$. Ibid., lettre de la légation de France à Bucarest au Département, 14 janvier 1948, ff. 178-179. 
Les préoccupations de la légation sont donc doubles : d'un part, elle entend préserver et même amplifier le maigre avantage que possède le film français sur le marché roumain en intervenant au plan économique et d'autre part, elle prête attention aux conditions de la censure roumaine. Toutefois, la légation n'est pas disposée à faire l'impasse sur la qualité, objectif majeur de la politique culturelle française à l'étranger ${ }^{61}$. Elle n'est pas prête non plus à jouer le rôle de médiateur ou à négocier les conditions d'achat des films au bénéfice de n'importe quelle société. C'est ainsi qu'elle met en garde la société française Cofranex : «la diffusion en Roumanie à bas prix des films français de seconde ordre n'est susceptible de recevoir aucune assistance de notre part, même si le contrôle de change français a par avance autorisé le transfert $^{62} »$. Cela n'empêche pas l'arrivée sur les écrans roumains des films français de "second ordre », mais ceux-ci ne profitent pas localement de l'appui diplomatique. Cet avertissement venant de la légation démontre la volonté du ministre de France en Roumanie, Jean Paul-Boncour ${ }^{63}$, de préserver et de soutenir en premier lieu la qualité française, quitte à perdre des opportunités économiques.

La légation devient par ailleurs le porte-parole des sociétés françaises dans leurs litiges financiers avec les sociétés roumaines. La nationalisation du commerce des produits cinématographiques, en novembre 1948, crée un contexte qui suscite de nombreux litiges. La manière dont la légation s'adresse aux autorités roumaines pour récupérer les bénéfices dus par la société roumaine Memento film à la société française Zenith, pour l'exploitation des films Le capitaine Fracasse d'Abel Gance (1943) et Graine au vent de Maurice Gleize (1944) démontre de la ténacité et la volonté de ne pas rendre les armes sans combattre. À partir de décembre 1948 et jusqu'en mai 1951, la légation revient régulièrement à la charge auprès des autorités roumaines compétentes - soit les responsables de Cinexfilm et de Romfilm, nouvelle société qui remplace Cinexfilm en mars 1949 pour la production et l'importation, ainsi que ceux du ministère des Affaires étrangères - pour récupérer la somme de 387766 de francs ${ }^{64}$. Alors que ses lettres restent dans un premier temps sans réponse, la légation leur propose de céder les droits d'exploitation pour deux films français, Volpone de Maurice Tourneur (1941) et Gai Paris: Vedettes de Paris de Lucette Gaudard (1946) présents dans ses stocks et disponibles pour une exploitation immédiate. Quelle est donc la logique de cette stratégie qui semble n'avoir aucune chance de réussite dans le contexte de rupture des relations franco-roumaines ? Le conseiller français anticipe-t-il en fait l'échec de ses réclamations financières et donne-t-il aux autorités roumaines la possibilité de compenser cette lourde dette en acquérant des films français? Difficile de répondre, mais la démarche semble porter certains fruits, car Volpone apparaît dans la programmation des salles roumaines dès 1951, aux côtés d'autres productions françaises, comme Sans laisser d'adresse de Jean-Paul Le Chanois (1951), Ruy Blas de Pierre Billon (1948) et Jour de fête de Jacques Tati (1949) ${ }^{65}$. L'implication de la légation dans la promotion du film en Roumanie annonce, d'une certaine manière, l'attribution

\footnotetext{
61. Annie Guénard, La Présence culturelle..., op. cit., pp. 174, 223.

62. AMAE-La Courneuve, 201QO/38, lettre de la légation de France à Bucarest au Département, $1^{\text {er }}$ août 1947, f. 88 .

63. Jean Paul-Boncour, diplomate de carrière, travaillant au service de la Société des Nations entre 1924 et 1934, neveu du ministre Joseph Paul-Boncour, occupe les fonctions de ministre de France à Bucarest de mars 1945 à 1948. Il est perçu par son collaborateur et directeur de l'Institut français de Bucarest, Jean Mouton, comme étant " en contact étroit avec les Russes» et entretenant de bonnes relations avec eux. (Jean Mouton, Journal de Roumanie, Lausanne, Éditions l'Age de l'homme, 1991, p. 103).

64. AMRAE, Fonds Franţa, 29. Dossier, Nr. 214, Datoria casei de film Memento, către firma Zenith din Paris, correspondance.

65. Archives du ministère roumain de la Culture de Roumanie (ci-après : ARMC), cartons Dir. P. Cinematogr., 1951, dossiers 1-4, 5-6.
} 
par le Quai d'Orsay, à partir de 1949, d'une place plus importante aux films de fiction dans les politiques internationales françaises ${ }^{66}$.

\section{ÉPILOGUE : LA DÉNONCIATION DE L’ACCORD CULTUREL FRANCO-ROUMAIN}

Les signes d'une rupture profonde entre les deux pays apparaissent à fin du juin 1948 dans une suite de mesures dirigées contre les différentes formes de coopération francoroumaines ${ }^{67}$. L'apogée en est constitué par la dénonciation, en novembre 1948, de l'accord « pour le développement des relations intellectuelles entre la France et la Roumanie » de 1939 par le gouvernement roumain. C'est un mois noir pour la France en Roumanie, tous les journaux nationaux dénonçant l'accord à l'unisson et se livrant à des critiques acerbes à l'adresse de la France, sur sa politique culturelle et économique en Roumanie. Le résultat immédiat de la dénonciation de l'accord culturel a été dramatique pour la partie française qui perd la plupart de ses structures de diffusion culturelle (Institut, écoles, bibliothèques) et le personnel nombreux attaché à ces institutions. Les officiels français à Bucarest le ressentent comme « une volonté d'anéantir l'influence [française] profonde en Roumanie $»{ }^{68}$. Par comparaison avec la manière dont se déroule le même processus dans les autres démocraties populaires, l'éviction française est particulièrement brutale en Roumanie ${ }^{69}$. Lucreţiu Pătrăşcanu, ministre de la Justice, qui pressentait dès janvier 1947 une violente réaction contre la culture française, en explique ainsi les raisons profondes au directeur de l'Institut culturel français, P. Rebeyrol :

Nous sommes, pour le présent, orientés vers l'Est. Vous ne devez pas attacher une excessive importance aux aigreurs de la presse roumaine contre la France, ni aux attaques qu'elle contient parfois et qu'elle contiendra dans l'avenir prochain contre la culture française ; elles sont motivées par la profondeur de l'influence française. C'est parce que la Roumanie est francisée que la culture française est attaquée. Vos succès sont les plus dangereux arguments contre vous ${ }^{70}$.

Du côté français, les représentants diplomatiques vivent l'anéantissement des instruments d'action culturelle comme un cataclysme, ainsi qu'il ressort de plusieurs rapports de diplomates. Par exemple, la note de la Direction générale politique du Ministère des Affaires étrangères " au sujet des relations entre la France et la RPR » témoigne surtout de l'amertume de la diplomatie française face à la disparition d'un monde :

Rarement un pays a eu à l'étranger une position plus éminente que celle que la France s'était créée en Roumanie. L'attachement à notre pays n'était pas seulement la préoccupation des milieux dirigeants, mais était également en honneur dans les masses paysannes et ouvrières. Pour la plupart des Roumains, la France était une seconde patrie et notre langue un autre mode d'expression nationale ${ }^{71}$.

La politique anti-française touche de plein fouet le film français qui est réduit au minimum : cinq films importés en 1949 contre trente-huit en 1947 et vingt-deux en 1948, selon le Centre national du cinéma français ${ }^{72}$. Les films français (fictions et documentaires)

66. Robert Frank, « La machine diplomatique culturelle après 1945 », Relations internationales, $\mathrm{n}^{\circ}$ 115, 2003, p. 325.

67. Annie Guénard, La Présence culturelle..., op. cit., p. 735.

68. AMAE-La Courneuve, 201QO/38, lettre de la légation de France à Bucarest au Département, 5 mai 1949, ff. $358-365,359$

69. Annie Guénard, La Présence culturelle..., op. cit., pp. 734-739.

${ }^{70}$. AMAE-La Courneuve, 201QO/38, rapport sur l'entretien avec le ministre de la Justice, 30 janvier 1948, f. 185 .

71. Ibid., 201QO/101, lettre de la légation de France à Bucarest au Département, 12 mars 1953, f. 652.

${ }^{72}$. Georges Pistourius, Destin de la culture française dans une démocratie populaire. La présence française en Tchécoslovaquie 1948-1956, Paris, Les iles d'or, 1957, p 273. 
mentionnés dans les registres de la Commission de censure roumaine en 1949 sont un peu plus nombreux : Les frères Bouquinquant de Louis Daquin (1948), Les casse-pieds de Jean Dréville (1948), Le point du jour de Louis Daquin (1949), La révolution de 1848 de Marguerite de la Mure et Victoria Mercanton (1948), Aubervilliers d'Eli Lotar (1946), La vie de Pasteur et Le combat des mineurs (non identifiés). Si les films français importés par Filmul Popular en 1946 et 1947 n'étaient pas sélectionnés sur des critères idéologiques, les films importés en 1949 témoignent d'un tournant important car ces films revendiquent totalement l'étiquette communiste tant du fait de leurs réalisateurs (Daquin, Le Chanois) que de leurs sujets.

Le Quai d'après 1949 en est réduit à suivre les conseils dispensés en janvier 1947 par Pătrăşacanu : " attendre, vivre, durer, en évitant toute manifestation spectaculaire ${ }^{73}$ ». Mais si la situation se dégrade fortement, les œuvres françaises jouissent encore d'une bonne réputation ${ }^{74}$. Leur situation reste avantageuse si on la compare à celle du cinéma hollywoodien, qui est totalement évincé des écrans roumains. Avant la reprise des relations culturelles francoroumaines du milieu des années 1950, la diffusion ou la rediffusion, même par intermittence, de films français puisés dans les anciens dépôts ou importés de manière contrôlée, permettent de maintenir en éveil les sensibilités francophiles de Roumanie et de satisfaire le besoin d'une alternative aux films soviétiques.

\section{CONCLUSIONS}

Globalement, la présence du film français sur les écrans roumains après la Seconde Guerre mondiale résulte d'initiatives de sociétés privées roumaines, françaises ou d'autres origines, auxquelles les services diplomatiques des deux parties apportent un soutien régulier à partir de 1946. La place réservée aux productions françaises par les autorités roumaines diminue d'une année sur l'autre à mesure que se dégradent les relations Est-Ouest, ce qui entraîne chez les diplomates français un engagement plus ferme et plus suivi en faveur du film, tant auprès des sociétés françaises d'exportation et du ministère des Affaires étrangères de Paris que des multiples acteurs institutionnels roumains. L'action de la légation se transforme, à partir de l'automne 1947 et jusqu'à la dénonciation de l'accord culturel, en un combat acharné pour trouver des brèches dans les barrières idéologiques imposées à l'importation des films occidentaux.

En face, la réaction roumaine témoigne surtout de l'évolution politique des gouvernements et de la montée des tensions internationales. Après une période durant laquelle les échanges cinématographiques semblent reprendre leur cours d'avant-guerre, le gouvernement communiste met en place à partir de 1948, avec l'appui des conseillers soviétiques, une politique cinématographique de diffusion et de production qui signifie non seulement une prise en charge de ces domaines par l'État, mais aussi un changement de la perception du cinéma : son rôle n'est plus de divertir mais d'éduquer, d'où la préférence donnée aux films à « fonds progressiste ». C'est sur ce point que la stratégie de la diplomatie française, mais aussi l'image progressiste de la France, jouent un rôle important pour le maintien de quelques films français dans la programmation des salles roumaines, au-delà même de la date de l'éviction des institutions culturelles de Bucarest et de leur personnel. Et c'est par ce même biais que le film français revient sur les écrans roumains à partir du milieu des années 1950 .

\footnotetext{
73. AMAE-La Courneuve, 201QO/38, rapport sur l'entretien avec le ministre de la Justice, 30 janvier 1948 , f. 186.

${ }^{74}$. Francesco Guida, « Une brèche dans le rideau de fer : le cinéma italien dans les pays du bloc soviétique au début de la Guerre froide », in Jean-François Sirinelli, Georges-Henri Soutou (dir.), Culture et guerre froide, Paris, Presses Paris Sorbonne, 2008, p. 210.
} 